\section{Cido de $\mathrm{K}$ rebs C omo Fator Limitante na U tilização de Á ci dos G raxos D urante o Exercício A eróbico}

\section{RESUMO}

Os ácidos graxos (AG) representam uma fonte importante de energia durante exercícios de intensidade leve ou moderada, e principalmente naqueles de duração prolongada. A utilização dos AG pelos músculos esqueléticos depende de passos importantes como a mobilização, transporte via corrente sangüínea, passagem pelas membranas plasmática e mitocôndrial, $\beta$-oxidação e, finalmente, a oxidação no cic lo de Krebs e atividade da cadeia respiratória. O exercício agudo e o treinamento induzem adaptações que possibilitam maior aproveitamento dos AG como fonte de energia, ao mesmo tempo em que o glicogênio muscular é preservado. Contudo, as tentativas de manipulação da dieta e suplementação com agentes ativos para aumentar a mobilização e utilização dos AG durante o exercício não apresentam resultados conclusivos. Nesse trabalho, a hipótese de que o ciclo de Krebs é o fator limitante da utiliza ção de ácidos graxos pelo tecido muscular no exercício prolongado é apresentada. (Arq Bras Endocrinol Metab 2003;47/2:135-143)

Descritores: Exercício; Oxidação de ácidos graxos; Agentes lipolíticos; Cic lo de Krebs; Glicogênio

\section{ABSTRACT}

The Krebs Cycle as Limiting Factor for Fatty Acids Utilization During Aerobic Exercise.

Fatty acids are important fuels for muscle during moderate and prolonged exercise. The utilization of fatty acids by skeletal muscle depends on important key steps such a slipolysis in the a dipose tissue, plasma fatty acids transport, and passage through plasma and mitochondrial membranes, $\beta$-oxidation, and finally oxidation through the Krebs cycle and respiratory chain activity. Acute exerc ise and exercise training induce adaptations that lead to an increase in fatty acid oxidation. As a result muscle glycogen is preserved. Nevertheless, diet manipulation and supplementation with lipolytic a gents that raise fatty acids mobilization and oxidation during exercise failed to show beneficial results on exerc ise performance. The hypothesis that Krebs cycle is a limiting factor for fatty acid oxidation by the skeletal muscle during prolonged exercise is presented herein. (Arq Bras Endoc rinol Metab 2003;47/2:135-143)

Keywords: Exerc ise; Fatty acid oxidation; Lpolytic agents; Krebs cycle; Glycogen
R ui Curi

Cláudia J. Lagranha Jair R odrigues G. Jr Tania Cristina Pithon-C uri Antonio $\mathrm{H}$ erbert Lancha J $r$ Í dico L. Pellegrinotti Joaquim Procopio

Laboratório de Fis ologia Celular (RC, CJL, JP), D epartamento de Fisiologia e Biofísica, Instituto de

Ciências Biomédicas,

U niversidade de São Paulo;

D epartamento de E ducação Física (JRGJ), U niversidade Estadual Paulista "Julio de M esquita

Filho", Bauru; U niversidade M etodista de Piracicaba (TCPC, ILP), FACEF, Piracicaba; U nicastelo (TCPC), São Paulo e; Escola de E ducação Física

(AH LJ r.), D epartamento de Biodinâmica do M ovimento do Corpo H umano, U niversidade de São Paulo, SP. 
0 EXERCício físico demanda intenso consumo de trifosfato de adenosina (ATP), que pode aumentar em até dezenas de vezes dependendo da intensidade e duração do esforço. N os músculos esqueléticos, há sistemas muito eficientes que possibilitam a ressíntese constante do ATP que está sendo utilizado para a contração muscular. Estes sistemas são o da fosfocreatina, glicólise e a fosforilação oxidativa. Este último é o mais complexo dos três e depende da utilização do oxigênio. Tem como característica baixa produção, porém capacidade praticamente ilimitada, sendo apto a fornecer energia para a ressíntese de ATP, principalmente em esforços de longa duração com intensidades leve ou moderada. N esta condição, o glicogênio é preservado havendo maior utilização dos ácidos graxos (AG) como substrato energéticos (1).

Essa preferência dos músculos esqueléticos pelos AG é muito importante em exercícios físicos de longa duração, já que os lipídios armazenados no organismo na forma de triacilglicerol (TG) representam o principal estoque de energia disponível (2). Por outro lado, o glicogênio, imprescindível durante 0 exercício físico, possui um estoque relativamente limitado, que necessita ser preservado para continuar sendo utilizado concomitantemente aos AG, porém em menor proporção, até o final do esforço.

Os TGs estão estocados principalmente no tecido adiposo $(\sim 17.500 \mathrm{mmol}$ em um homem adulto, magro), músculo esquelético $(\sim 300 \mathrm{mmol})$ e plasma $(\sim 0,5 \mathrm{mmol})$. 0 total de energia estocada como TG é cerca de 60 vezes maior que aquela como glicogênio. D esta forma, a oxidação dos AG durante o exercício possibilita manter a atividade física por períodos mais prolongados e retarda a depleção do glicogênio e a hipoglicemia.

Nos exercícios físicos de longa duração, é imprescindível que a utilização do estoque abundante de TG / AG seja a maior possível justamente para que a quebra do glicogênio muscular e a oxidação de glicose circulante sejam as menores possíveis. A hipótese que parece melhor explicar esse "desvio" do metabolismo dos carboidratos para os lipídios é o ciclo de Randle (3). Com o aumento da disponibilidade de AG há maior oxidação deste diminuindo paralelamente a degradação de glicogênio e a utilização de glicose. Os AG desempenham assim papel crítico na manutenção da atividade física e, por isso, uma etapa limitante desta atividade é a lipólise.

0 estoque de glicogênio muscular é suficiente para pouco mais de uma hora de esforço de intensidade moderada, fazendo com que os músculos dependam também da captação de glicose circulante para manter a contração. Por sua vez, a manutenção da glicemia é fundamental, principalmente para preservar a função cerebral durante exercícios prolongados, nos quais se observa diminuição da glicemia para até cerca de $40-50 \mathrm{mg} \cdot \mathrm{dL}^{-1}$, levando 0 indivíduo à exaustão (4). Por isso, ajustes ocorrem para aumentar a eficiência na mobilização dos AG a partir do tecido adiposo, que é um estoque abundante.

\section{Os depósitos energétic os do organismo}

O s lipídios armazenados representam a fonte corpórea mais abundante de energia potencial. Em relação aos outros nutrientes, a quantidade de lipídios disponível para a produção de energia é quase ilimitada. No homem, uma massa aproximada de $9000 \mathrm{~g}$ de lipídios é suficiente para fornecer $81000 \mathrm{Kcal}$. Este estoque permitiria a um homem adulto andar 259 horas ou correr durante 67 horas. Por outro lado, o estoque de glicogênio muscular $(350 \mathrm{~g})$ fornece $1400 \mathrm{Kcal}$, permitindo caminhar apenas 4,8 horas ou até mesmo correr durante 1,2 horas (2).

O s AG, estocados na forma de TG, representam a principal reserva energética disponível no homem. 0 armazenamento de TG é ilimitado, já que a esterificação dos AG com o glicerol não depende de água, diferentemente do glicogênio que é estocado com $3 \mathrm{~g}$ de água para cada grama do polímero. 0 utra vantagem dos AG é sua eficiência energética ( $\left.9 \mathrm{~K} \mathrm{cal.} \mathrm{g}^{-1}\right)$, mais que 2 vezes a do glicogênio/ glicose (4K cal. $\left.\mathrm{g}^{-1}\right)$ (5). Por esses motivos, e de acordo com a primeira lei da termodinâmica (lei da conservação de energia), todo excesso de energia proveniente da alimentação, incluindo gorduras, carboidratos e proteínas, é armazenado na forma de TG.

\section{Mobilização e captação dos ácidos graxos nos músc ulos esquelétic os}

As fontes de $A G$ para utilização nos músculos esqueléticos são o TG do tecido adiposo, o TG dos quilomicrons e lipoproteínas de muito baixa densidade (VLDL) circulantes, e o TG do próprio tecido muscular que pode atingir uma quantidade de cerca de $400 \mathrm{~g}$ em indivíduos treinados (5).

A mobilização dos AGL a partir do tecido adiposo é dependente da taxa de lipólise, da capacidade de transporte dos AGL pelo plasma e da reesterificação desses pelos adipócitos.

A atividade lipolítica do tecido adiposo aumenta com o exercício (6), em particular no treinamento aeróbio, que resulta em um aumento significativo no número e na atividade das mitocôndrias além de um aumento na oxidação de AGL. Contudo, em alguns 
estudos foi sugerido que a noção de que o treinamento sempre aumenta a eficiência da utilização dos AGL durante o exercício (7) pode não ser correta. Turcotte e cols. (8) mostraram que a captação de AGL do plasma é significativamente maior em homens treinados do que em não treinados, durante 3 horas de exercício. Esses dados são sugestivos de que a captação de AGL pelo músculo esquelético é mediada por um transportador saturável e que o treinamento aumenta a capacidade máxima para o transporte de AGL no músculo esquelético, possivelmente por elevar o conteúdo de carreadores de AG.

Ainda não está muito bem estabelecida qual é a principal fonte de AG disponíveis para oxidação nos músculos esqueléticos. Alguns autores sugerem que 0 treinamento aumenta a atividade de degradação do triacilglicerol intramuscular (TGIM) em relação ao estocado no tecido adiposo (5). Foi observado que 0 conteúdo intramuscular de TG aumenta com o treinamento (5) e pode diminuir de $25 \%$ a $50 \%$ durante 0 exercício prolongado de intensidade de $55 \%$ a $75 \%$ do $\mathrm{VO}_{2 \text { máx. }}$ (9). U ma vantagem significativa da utilização do TGIM é que as etapas de transporte dos AG no plasma e sua passagem através da membrana da célula muscular não são necessárias e, portanto, a sua oxidação é mais rapidamente disparada.

Em relação aos $A G$ provenientes do tecido adiposo, o primeiro passo para sua utilização é a mobilização, ou seja, a hidrólise do TG. O metabolismo do adipócito é controlado por hormônios e pelo sistema nervoso. De um lado, a insulina inibe a lipólise e estimula o processo de lipogênese e esterificação (10). Por outro lado, a mobilização dos AG é estimulada pela ação da adrenalina, noradrenalina, cortisol e hormônio do crescimento ( $\mathrm{GH}$ ). Em adipócitos de ratos, as catecolaminas, glucagon, hormônio do crescimento e os hormônios adrenocorticotrópicos aumentam a lipólise (5), mas em adipócitos isolados de humanos apenas as catecolaminas, hormônio estimulador da tireóide e paratormônio têm mostrado efeito lipolítico consistente (11).

Apenas as catecolaminas podem estimular a lipólise no homem, em condições fisiológicas. As catecolaminas têm ação inibitória através de receptores $\alpha_{2}$ adrenérgicos e estimulatória via receptores $\beta_{1}$-adrenérgicos, por alterações correspondentes na atividade da adenilato ciclase e na produção intracelular de AM PC (12).

O exercício agudo promove liberação intensa dos hormônios lipolíticos e aumenta a responsividade dos receptores $\beta$-adrenérgicos dos adipócitos às catecolaminas (13). Em conseqüência, aumenta a mobi- lização e da concentração plasmática de AG, que é o passo determinante para sua maior oxidação nos músculos esqueléticos (3). Stich e cols. (14) demonstraram que trabalho aeróbio intermitente (como por

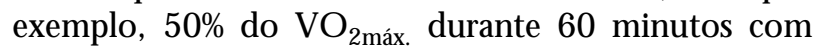
período de repouso semelhante entre uma sessão e outra) são mais eficientes na mobilização dos AG do que apenas uma sessão de esforço físico. No caso do treinamento, é observado um aumento na concentração plasmática de AG, porém a oxidação desses nos músculos esqueléticos depende da intensidade relativa do esforço (15).

Romijn e cols. (16) estudaram a mobilização e utilização de carboidratos e lipídios durante exercícios de diferentes intensidades (25\%, 65\% e $85 \%$ do $\mathrm{VO}_{2 \text { máx. }}$ ) em homens treinados. Como esperado, a captação de glicose pelos músculos e a glicogenólise intramuscular aumentaram proporcionalmente à intensidade do esforço. A lipólise e a conseqüente liberação dos $A G$ na circulação foram mais elevadas durante o exercício de menor intensidade. Por outro lado, a lipólise do TG intramuscular (TGIM) foi elevada com o aumento da intensidade do exercício. Resultados semelhantes foram encontrados, mais recentemente, no estudo dos mesmos parâmetros em mulheres treinadas (17).

\section{Metabolismo dos triacilgliceróis intramusculares (TGIM)}

Durante os primeiros 90min de exercício, a taxa lipolítica é aproximadamente 2 vezes maior do que a taxa de oxidação dos AG. No entanto, a entrada de AG no plasma é similar à taxa de oxidação no mesmo período. Alguns pesquisadores sugerem que outra fonte de lipídios, além dos AG provenientes do tecido adiposo, provavelmente plasmático ou TGIM , é também oxidada pelo músculo $(18,19)$.

Postula-se que a reserva mais importante de AGL não plasmáticos, disponível para a oxidação durante exercício moderado e prolongado, é o TGIM (20). E sses são encontrad os em concentrações diferentes conforme o tipo de fibra muscular, sendo armazenados em maior quantidade nas fibras musculares de contração lenta do que em fibras musculares de contração rápida (20). Além disso, o próprio treinamento faz com que a deposição de TG seja diferente entre os tipos de fibra muscular (20).

A regulação da hidrolíse dos TGIM parece estar, em grande parte, sujeita à estimulação $\beta$-adrenégica, em contraste com a lipólise do tecido adiposo, que é parcial mente inibida por bloqueadores $\beta$-adrenégicos. 
Conforme Cleroux e cols. (21), a utilização de $\beta$-bloqueador não seletivo resulta em inibição total da utilização de TG no músculo vasto lateral de humanos submetidos a trabalho no ciclo ergômetro. Conforme Stankiewicz-Choroszycha e Gorski (22), a utilização de $\beta$-bloqueador seletivo previne a diminuição na concentração de TG no músculo esquelético de ratos durante o exercício, enfatizando a importância da estimulação adrenérgica na regulação da hidrólise do TGIM . O efeito da adrenalina ocorre sobre as enzimas que atuam na hidrólise dos T G. O scai e cols. (23) propuseram que uma isoforma intracelular da lipase lipoproteica (LLP) atua como lipase de TG em músculo esquelético e coração. Evidências desta hipótese estão no fato de que a atividade da LLP intracelular está aumentada em músculo esquelético de ratos em exercício e que este incremento depende da intensidade do esforço (23).

O utros investigadores propõem que uma lipase sensível a hormônio, similar à lipase hormônio sensível (LHS) do tecido adiposo, pode regular a hidrólise intramuscular de TG (24). Esta proposição foi confirmada com a produção de anticorpos contra LHS purificada de tecido adiposo de ratos. Holm e cols. (25) constataram através de "imunoblotting" a presença de uma proteína com peso molecular similar a LHS do tecido adiposo em extrato de músculo esquelético de ratos.

Recentemente, Guo e cols. (26) avaliaram, no músculo vasto lateral de 12 adultos, a cinética de TGIM e de AGL durante o exercício moderado ( $45 \%$ do $\left.V \mathrm{O}_{2 \text { máx. }}\right)$. Nesse estudo, não foi observada diminuição significativa no conteúdo de TGIM em resposta ao exercício. Os autores sugerem que, durante o exercício de duração e intensidade moderada, o TGIM é simultaneamente hidrolisado e reesterificado e assim a concentração deste é mantida praticamente constante.

A razão para as divergências quanto à importância dos T GI M durante o exercício ainda não está clara. Tais divergências talvez reflitam variações decorrentes de protocolos e variabilidade nas técnicas para determinar a concentração do TGIM muscular (27).

\section{Oxidação dos ácidos graxos nos músculos esqueléticos}

No sarcoplasma, os AG precisam atravessar mais uma barreira, representada pelas membranas externa e interna da mitocôndria, a fim de serem oxidados. Ainda no citossol, os AG são ativados (figural), recebendo uma coenzima $A(C O A)$ e tornando-se acilCoA numa reação catalisada pela enzima acil-C oA sin-

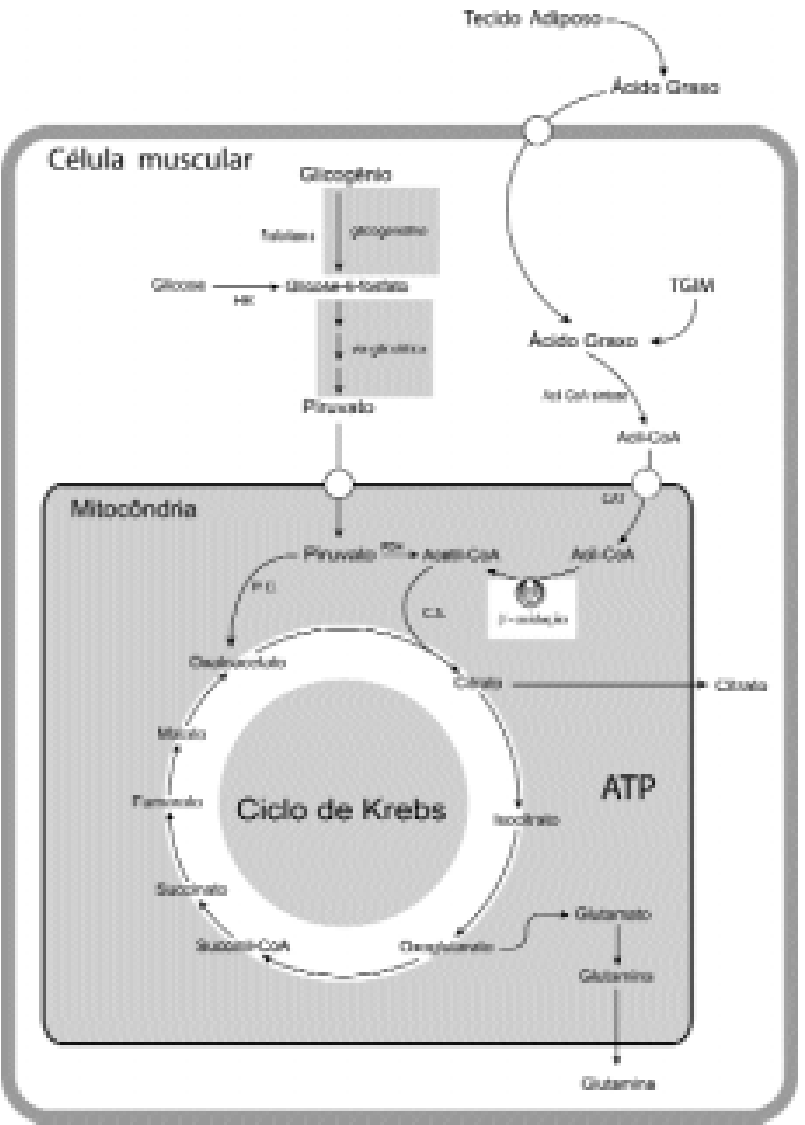

Figura 1. Ciclo de Krebs: O pinuvato gerado a partir de glicose e glicogênio é transportado para o interior da mitocôndria. Nesta, o pinuvato é convertido em oxalacetato via piruvato carboxilase e em acetil $C o A$ via piruvato desidrogenase. $O$ acetil CoA é também proveniente da $\beta$ oxidação de ácidos graxos. O a cetil-CoA e o oxalac eta to geram citrato pela citrato sintetase. O citrato proveniente do ciclo de Krebs é parcialmente transportado para o citossol. O oxog lutara to é convertido em glutama to e este em glutamina. Assim, nesses dois mecanismos, há perda continua de esqueletos de carbono do ciclo de Krebs. Em conseqüência, a geração de oxaloacetato é uma etapa importante para manter a atividade deste ciclo.

$\mathrm{CS}=$ citrato sintetase; $\mathrm{HK}=$ hexoquinase; $\mathrm{PC}=$ piruvato carboxila se; $\mathrm{PDH}=$ pinuva to desc a rb oxila se; $\mathrm{CAT}=$ a c ilc a mitina transferase; TG IM = trig lic eńd eos intra musc ula res.

tetase (28). 0 acil-CoA atravessa as membranas mitocondriais por meio de um processo dependente de carnitina e das enzimas carnitina acil transferase I (CAT I), localizada na membrana externa, carnitina acil transferase II (CAT II), localizada na membrana interna e carnitina-acilcarnitina translocase (29), que atua entre as duas. As duas primeiras enzimas são também denominadas carnitina palmitoil transferase I e II (CPT I e II), devido ao fato do ácido palmítico ser o principal ácido graxo metabolizado nos músculos esqueléticos (30). 
Os passos para a entrada do acil-CoA na mitocôndria são os seguintes: a CAT I promove a ligação do acil com a carnitina, formando acil-carnitina, ao mesmo tempo que a $\mathrm{CoA}$ é liberada (figura 1). Por meio da ação da carnitina-acilcarnitina translocase, o complexo acil-carnitina atravessa a membrana externa, o espaço intermembranas e a membrana interna, onde a CAT II rompe o complexo acil-carnitina, liberando a carnitina e restabelecendo a ligação acil-COA (31).

0 passo seguinte é a entrada da molécula de acil-CoA no processo de $\beta$-oxidação que consiste na remoção sucessiva de pares de carbonos e formação de um certo número de moléculas de acetil-CoA proporcional ao de carbonos do ácido graxo original. Durante a $\beta$-oxidação são liberados íons $\mathrm{H}^{+}$e elétrons, reduzindo as flavoproteínas NAD ${ }^{+}$e FAD em NADH $+\mathrm{H}^{+} \mathrm{e} F A D \mathrm{H}_{2}$, para sua posterior utilização na cadeia respiratória. Além disso, o acetil-COA resultante é metabolizado no Ciclo de K rebs, onde há a redução de outras flavoproteínas. Como já mencionado, o exercício é uma situação na qual há aumento significativo da liberação de hormônios que estimulam a lipólise, e aumenta a concentração plasmática de AG. A maior disponibilidade de $A G$ circulantes aumenta proporcionalmente sua captação e utilização pelos músculos esqueléticos $(3,32)$. Entretanto, essa relação ocorre apenas quando o esforço é leve ou moderado. Sabe-se que, acima de $70 \%$ (33) e $85 \%$ (34) do $\mathrm{VO}_{2 \text { máx, }}$ a mobilização de AG é diminuída, provavelmente devido ao aumento da concentração plasmática de lactato, um metabólito anti lipolítico (5).

Exercício físico com intensidade moderada ( $25 \%$ a $65 \%$ do $V_{2 \text { máx. }}$ ), quando comparado ao repouso, aumenta em cerca de 5 a 10 vezes a oxidação de ácidos graxos, devido à alta demanda energética dos músculos ativos e disponibilidade dos AG provenientes da lipólise do tecido adiposo. N esta condição, há aumento de 2 a 3 vezes da lipólise (6), mediada pela estimulação $\beta$-adrenérgica (35). Além disso, a porcentagem de liberação dos AG que são reesterificados diminui pela metade (6), provavelmente devido às alterações do fluxo sangüíneo que facilitam a remoção dos $A G$ do tecido adiposo para os músculos ativos. 0 exercício de intensidade moderada dobra o fluxo sangüíneo no tecido adiposo e causa aumento maior que 10 vezes deste no músculo esquelético (18).

D urante exercício prolongado com intensidade de $40 \%$ do $\mathrm{VO}_{2 \text { máx, a oxidação de ácidos graxos }}$ aumenta e permanece elevada durante pelo menos uma hora no período de recuperação. Em exercícios prolongados com intensidade de $70 \%$ do $\mathrm{VO}_{2 \text { máx. }}$, cerca de $50-60 \%$ da energia é suprida pelos car- boidratos, com utilização predominante nos primeiros 30-40 minutos do esforço. 0 restante da energia (40$50 \%$ é suprido pelos $A G$ que têm sua concentração plasmática e oxidação muscular aumentadas progressivamente, tornando-se o substrato mais utilizado pelos músculos a partir de 40-50 minutos de esforço e até várias horas enquanto este se prolonga (32). A contribuição dos AG para o metabolismo muscular em exercícios prolongados de intensidade moderada ( $75 \%$ do $\mathrm{VO}_{2 \text { máx. }}$. pode ser confirmada pelo fato de que a concentração de acilcarnitina aumenta em cerca de três vezes durante 0 esforço e se mantém elevada até a exaustão (36).

O s tipos de exercícios físicos que se beneficiam de forma significativa do metabolismo dos AG são aqueles com duração superior a 30 minutos e que se prolongam por algumas horas. Como já mencionado, a intensidade é um fator determinante na mobilização e utilização do glicogênio/glicose e TG/AG, visto que há uma relação direta entre a intensidade do esforço e a utilização de glicose como substrato (16). De modo geral, indivíduos bem treinados podem manter uma intensidade de $80-85 \%$ do $\mathrm{VO}_{2 \text { máx. }}$ durante pouco mais de 2 horas, como numa corrida de maratona, por exemplo, devido ao aumento do estoque de glicogênio nos dias precedentes à prova, e à capacidade elevada de utilização dos AG pelos músculos (32). N estes indivíduos, os triacilgliceróis dos próprios músculos esqueléticos representam uma fonte importante de AG para a oxidação. Alguns pesquisadores sugerem que $o$ treinamento não aumenta a oxidação dos AG provenientes do plasma mas, provavelmente, do estoque de TGIM .

Além da utilização dos AG durante o exercício, no período de recuperação, quando o estoque de glicogênio está acentuadamente diminuído e a atividade metabólica continua aumentada, os AG constituem o principal substrato energético utilizado.

\section{Suplementação com ácidos graxos e facilitadores de sua utilização}

A manipulação da dieta e suplementação com certos tipos de lipídios ou outros agentes que estimulam a lipólise e oxidação dos $A G$, vem sendo estudados como estratégias para melhorar o desempenho no exercício.

$\mathrm{H}$ agerman (32) sugeriu que uma manipulação dietética, no sentido de aumentar o fornecimento de lipídios, pode ser benéfica para indivíduos treinados pois aumenta os estoques intramusculares de TG. Dietas ricas em lipídios apresentam resultados controversos; em alguns casos apontando aumento e, em 
outros, diminuição do desempenho físico, em comparação com dietas balanceadas ou ricas em carboidratos (5). D ietas ricas em lipídios aumentam a atividade da $L L P$, que catalisa a degradação do TG circulante aumentando a disponibilidade de AG para os músculos ativos. $\mathrm{No}$ entanto, o exercício agudo por si só estimula a LLP (37). Também se menciona que há um aumento do metabolismo lipídico durante o exercício de intensidade de $60-80 \% \mathrm{VO}_{2 \text { máx. }}$ após o consumo de dietas ricas em lipídios por apenas alguns dias (38); entretanto, esse pode ser simplesmente um efeito da diminuição da disponibilidade de carboidratos.

$\mathrm{H}$ á consenso contudo de que o desempenho no exercício aumenta após alguns dias consumindo uma dieta rica em lipídios seguida pelo consumo de uma dieta rica em carboidratos três dias antes do esforço físico. Esta é a dieta de supercompensação, proposta por Bergström e cols. (39) há mais de 30 anos, e está mais diretamente relacionada ao aumento da disponibilidade de glicogênio muscular do que da utilização dos AG.

No início da década de 80 , I vy e cols. (4) compararam o efeito de $30 \mathrm{~g}$ de triacilglicerol de cadeia média (TCM) com a mesma quantidade de triacilgliceróis de cadeia longa (TCL), a humanos, quando administrados juntamente com carboidratos durante exercício de uma hora a $70 \%$ do $\mathrm{VO}_{2 \text { máx. }}$. Verificou-se uma contribuição para o metabolismo energético de $37 \%$ dos TCM e $39 \%$ dos TCL. Esses valores estão abaixo daqueles da contribuição dos lipídios durante a realização do exercício em jejum que é de $49 \%$ Nesse caso, a suplementação com TCM e TCL provavelmente não aumentou a proporção de lipídios metabolizados, pois os carboidratos inibem o metabolismo lipídico $(3,40)$.

A carnitina, como visto anteriormente, é um agente importante na oxidação dos AG, atuando no seu transporte para o interior da mitocôndria. N este sentido, D ecombaz e cols. (41) estudaram o efeito da suplementação de L-carnitina ( $3 \mathrm{~g} \cdot \mathrm{d}^{-1}$ durante 7 dias) sobre o metabolismo de lipídios durante exercício a $57 \%$ do $\mathrm{VO}_{2 \text { máx. }}$ após a depleção prévia do glicogênio. Em relação ao grupo que recebeu placebo, não foram observadas diferenças nos parâmetros sangüíneos, quociente respiratório (indicativo do substrato utilizado), freqüência cardíaca e detecção de fadiga, levando os autores a concluírem que a suplementação de carnitina não altera o metabolismo energético, mesmo durante um exercício de intensidade moderada realizado após a depleção do glicogênio.

Em um estudo de Yan e cols. (29), foi demonstrado que o aumento da atividade contrátil dos mús- culos esqueléticos, seja causado pelo exercício ou estimulação elétrica crônica, aumenta a expressão do RN Am da CAT II. Esses autores postulam que a carnitina, é obtida em quantidades suficientes numa dieta não vegetariana (42), tendo também sua síntese e aproveitamento aumentados.

\section{Agentes lipolític os utilizados por atletas}

A lipólise é principalmente regulada pelas catecolaminas, através de $\beta$-adrenorreceptores, que promovem elevação da concentração intracelular do AM PC ativando a proteina quinase A (PKA) (24). D esta forma, os principais agentes lipolíticos são aqueles que atuam na resposta dos $\beta$-adrenoreceptores, como a cafeína. Essa metil-xantina, além do seu efeito estimulante no sistema nervoso central aumentando a concentração plasmática de noradrenalina, estimula diretamente 0 processo lipolítico (5). A cafeína inibe a fosfodiesterase, aumentando a meia-vida do AM Pc e como conseqüência a atividade da proteína quinase $A$ (PKA) e da lipase sensível a hormônios (LSH). A dose que provoca esses efeitos é de $3-6 \mathrm{mgK} \mathrm{g}^{-1}$, enquanto que a dose de 8mgKg-1 é considerada "doping" e doses de $10-15 \mathrm{mgK} \mathrm{g}^{-1}$ são tóxicas, podendo provocar distúrbios gastrointestinais, arritmia, ansiedade e alucinações (43).

O utras drogas que podem atuar como lipolíticas são Clembuterol, Fenoterol, Salbutanol, Salmeterol, I soprenaline, D obutamina e demais substâncias que atuam via receptor beta adrenérgico (44).

\section{Regulação da oxidação de ácidos graxos pelo músc ulo esquelético quando há oferta abundante de glic ose}

A metabolização elevada da glicose pelo músculo esquelético reduz a oxidação de ácidos graxos. 0 efeito da glicose sobre a oxidação de ácidos graxos ocorre da seguinte maneira: a glicose ao ser metabolizada pela via glicolítica gera piruvato e este através da piruvato desidrogenase forma acetil CoA. Este condensa-se ao oxaloacetato pela citrato sintase levando à produção de citrato (2). Este sai da mitocôndria para o citoplasma e pela ação da ATP-citrato liase gera acetil CoA. O acetil CoA é convertido em malonil CoA pela acetil COA carboxilase. $O$ citrato é um ativador importante da acetil CoA carboxilase (48). Portanto, este metabólito além de precurssor ativa a produção de malonil CoA.

O malonil COA é um potente inibidor da CAT I (47). Assim, ocorre inibição da oxidação de ácidos graxos na mitocôndria (48). O s ácidos graxos que permanecem no citoplasma na forma de acil CoA são 
então esterificados em triglicerídeos, fosfolípides ou ésteres de colesterol $(48,49)$. Este mecanismo da interação glicose-ácidos graxos leva à redução da oxidação de ácidos graxos e o seu acúmulo como macromoléculas lipídicas.

\section{Fatores que limitam a atividade do ciclo de Krebs}

O ciclo de Krebs apresenta, como caracteristica peculiar, a geração de precursores e produtos com a liberação de $\mathrm{CO}_{2}$. Além disso, o ciclo libera metabólitos como citrato e glutamina. Há, portanto, uma perda contínua de esqueleto de carbono que precisa ser reposta. A síntese de oxalacetato é a etapa de inserção de novas moléculas no ciclo.

Durante o exercício, os principais substratos utilizados na reposição dos intermediários do ciclo de Krebs são o piruvato e aminoácidos como aspartato, asparagina e glutamato (45). Lancha Jr. e cols. (46) verificaram que, durante o exercício físico em ratos, ocorre ativação da piruvato carboxilase, enzima que converte piruvato em oxaloacetato. Este último metabólito condensa-se ao acetil-CoA e forma citrato, pela ação da citrato sintase, iniciando o ciclo de K rebs. Desse modo, são duas as principais limitações para maior utilização de AG no exercício de intensidade moderada e de longa duração: a disponibilidade de glicogênio para o fornecimento de intermediários do ciclo de Krebs (45) e a mobilização de AG do tecido adiposo e do músculo esquelético (5).

\section{Proposição do presente trabalho}

Conforme Bergstrom e cols. (39), o aumento do conteúdo de glicogênio muscular é um fator determinante para o desempenho no exercício aeróbio moderado e prolongado. Os ácidos graxos atuariam como fonte energética principal e o glicogênio para a manutenção da atividade do ciclo de Krebs na geração de oxalacetato (figura 1).

O fornecimento do oxalacetato seria, portanto, um fator limitante, já que o acetil CoA, proveniente do ácido graxo, reage com este para a formação de citrato, pela citrato sintase, com posterior fornecimento de ATP. Assim, ocorrendo redução de oxalacetato, a reação deste com acetil CoA para formar citrato é diminuída independentemente da oferta de acetil CoA derivada da mobilização aumentada de ácidos graxos do tecido adiposo (figura 2). H averia então, lipólise, aumento de ácidos graxos no plasma ou do próprio tecido com aumento da oferta desses ao músculo. A atividade reduzida do ciclo de Krebs, no entanto, limita a oxidação de ácidos graxos por este tecido. A

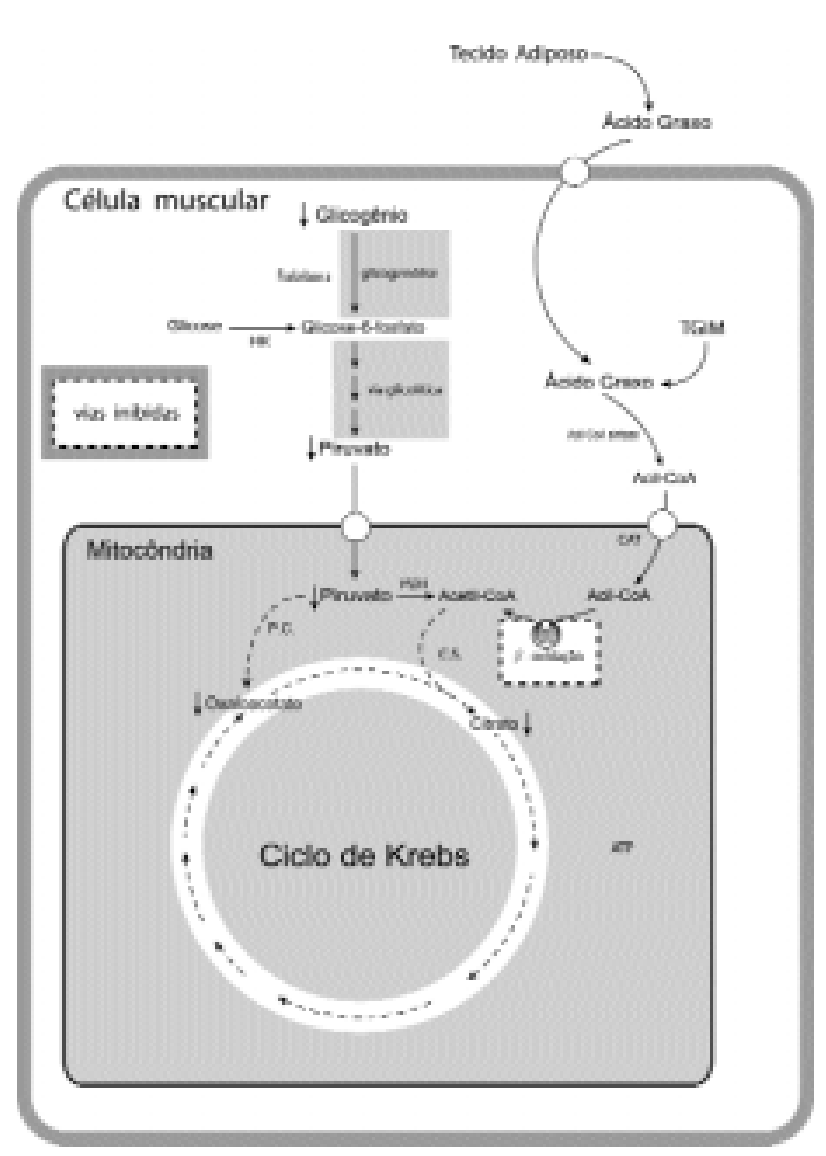

Figura 2. Hipótese do presente trabalho. Havendo redução do conteúdo de glicogênio e, conseqüentemente, na produção de piruvato ocorre a queda de oxalacetato. A reação deste com acetil-CoA para formar citrato fica reduzida independente da oferta de acetil-CoA derivada da mobilização aumentada de ácidos graxos no tecido a diposo. Assim, mesmo havendo oferta de ácidosgraxos, o músculo esquelético não consegue oxidar o acetil-CoA gerado na $\beta$-oxidação. Como conseqüência ocorre a redução na produção de ATP. Portanto, a exaustão do ciclo de Krebs seria o fator deteminante da exaustão no exercíc io físic o.

$\mathrm{HK}=$ hexoquinase; $\mathrm{CS}=\mathrm{c}$ itrato sintetase; $\mathrm{PC}=$ pinuvato $\mathrm{car}$ boxila se; $\mathrm{PDH}=$ pinuva to desc a rboxila se; $\mathrm{CAT}=$ a c ilc a mitina transferase; TG IM = trig lic eńd eos intra musc ula res.

exaustão do ciclo de Krebs se deve à perda de esqueleto de carbonos. Como conseqüência, há queda do ATP e ocorre a exaustão do indivíduo no esforço físico prolongado.

Os autores deste trabalho acreditam que a capacidade do músculo esquelético para oxidar ácidos graxos apresenta relação intima com a oferta e metabolização de glicose, quer seja esta proveniente do plasma ou da degradação do glicogênio muscular. Assim, a oxidação de ácidos graxos, para ser máxima, requer metabolização de glicose em taxas apropriadas. Situações de oferta muito elevada ou diminuída de gli- 
cose levam à redução da oxidação de ácidos graxos por mecanismos distintos. Quando a oferta de glicose é elevada, o malonil CoA gerado inibe a CPT -I. Por sua vez, na depleção de glicogênio, falta esqueletos de carbono para manter o fluxo de metabólitos pelo ciclo de Krebs funcionante.

\section{AGRADECIMENTO}

O s autores dedicam este estudo à memória da Professora Dra. Lor Cury, querida colega do D epartamento de Fisiologia e Biofísica, ICB-U SP.

Nosso grupo recebe suporte financeiro da FAPESP, CN Pq, CAPES e Pronex.

\section{REERÊNCIAS}

1. Wegener G, Krause U, Newsholme EA. Metabolic regulation - physiological and medical aspects. Experientia 1996;52:391-5.

2. Newsholme EA, Leech AR. Biochemistry for the medical sciences. New York: J ohn Wiley \& Sons, 1983.

3. Newsholme EA. An introduction to the roles of the glucose-fatty acid cycle in susta ined exerc ise. In: Maughan RJ, Shirreffs SM, editors. Biochemistry of exercise IX Human kinetics. Publishers: Champaign, 1996.

4. Ivy J L, Costill DL, van Handel PJ, Essig DA, Lower RW. Contribution of medium and long chain triglyceride intake to energy metabolism during prolonged exerc ise. IntJ Sports Med 1980;1:15-20.

5. Brouns F, van der Vusse GJ. Utilization of lipids during exerc ise in human subjects: metabolic and dietary constra ints. BrJ Nutr 1998;79:117-28.

6. Wolfe RR, Klein S, Carraro F, Weber JM. Role of triglycenide-fatty acid cycle in controlling fat metabolism in humans during and after exercise. Am J Physiol 1990;258:E382-9.

7. J ansson E, Kaijser L Substrate utilization and enzymes in skeletal muscle of extremely endurance-trained men. J Appl Physiol 1987;62:999-1000.

8. Turc otte LP, Richter EA, Kiens B. Increased plasma FFA uptake and oxidation during prolonged exercise in trained vs. untrained humans. Am J Physiol 1992;262:E791-9.

9. Richter EA, Kiens B, Turc otte LP. Transport and metabolism of fatty acid in muscle. In: Maughan RJ, Shirreffs SM, editors. Biochemistry of exerc ise IX, Human kinetic s Publishers: Champaign, 1996.

10. Campbell PJ, Carlson MG, Hill J O, Nurihan N. Regulation of free fatty acid metabolism by insulin in humans: role of lipolysis and reesterification. Am J Physiol 1992;263:E1063-9.

11. Bülow, J. Principles of exerc ise biochemistry 2nd; 1993.
12. Franz IW, Lohmann FW, Koch G, Quabbe HJ. Aspects of homonal regulation of lipolysis duning exerc ise: effects of chronic beta-receptor blockade. Int J Sports Med 1983;4:14-20.

13. Wahrenberg $H$, Engfeldt $P$, Bolinder I, Amer P. Acute adaptation in adrenergic control of lipolysis during physic al exercise in humans. Am J Physiol 1987;253:E383-90.

14. Stich $\mathrm{V}$, et al. Adipose tissue lipolysis is increased during a repeated bout of aerobic exercise. J Appl Physiol 2000;88:1277-83.

15. Friedlander AL, Casazza GA, Homing MA, Usaj A, Brooks GA. Endurance training increases fatty acid tumover, but not fat oxidation, in young men. J Appl Physiol 1999;86:2097-105.

16. Romijn J A, Coyle EF, Sidossis L Regulation of endogenous fat and carbohydrate metabolism in relation to exercise intensity and duration. Am J Physiol 1993;265:E380-91.

17. Romijn J A, Coyle EF, Sidossis LS, Rosenblatt J, Wolfe RR. Substrate metabolism during different exercise intesities in endurance-trained women. J Appl Physiol 2000;88:1707-14.

18. Martin WH, Dalsky GP, Hurley BF. Effect of endurance training on plasma free fatty acid tumover and oxidation during exercise. Am J Physiol 1993;265:E708-14.

19. Phillips SM, Green HJ , Tamopolsky MA, Heigenhauser GJ , Grant SM. Progressive effect of endurance training on metabolic adaptations in working skeletal muscle. Am J Physiol 1996;270:E265-72.

20. Abemethy PJ, Thayer R, Taylor AW. Acute and chronic responses of skeletal muscle to endurance and sprint exerc ise. Sports Medicine 1990;10:365-89.

21. Cleroux J, van Nguyen P, Taylor AW, Leenen FH. Effects of beta 1- vs. beta $1+$ beta 2 -blockade on exercise endurance and muscle metabolism in humans. J Appl Physiol 1989;66:548-54.

22. Stankiewicz-Choroszucha B, Górski J. Effect of decreased availability of substrates on intramuscular triglyceride utilization during exercise. Eur J Appl Physiol 1978; $40: 27-35$

23. Oscai LB. Type $L$ homone-sensitive lipase hydrolyzes endogenous triacylglycerols in muscle in exercised rats. Med Sci Sports Exerc 1983;15:336-9.

24. Severson DL Regulation of lipid metabolism in adipose tissue and heart. Can J Physiol Pharm 1979;57:923-37.

25. Holm C. Immunological evidences for the presence of homone-sensitive lipase in rat tissues other than adipose tissue. Biochem Biophys Res Commun 1987;148:99-105.

26. Guo Z, Burguera B, J ensen MD. Kinetic s of intramuscular triglyceride fatty acids in exercising humans. J Appl Physiol 2000;89:2057-64.

27. Wendling PS, Peters SJ, Heigenhauser GJ, Spriet $\amalg$ Varia bility of tria cylglyc erol content in human skeletal musc le biopsy samples. J Appl Physiol 1996;81:1150-5.

28. Groff J L, Gropper SS, Hunt SM. Advanced nutition and human metabolism. West Publishing Company: New York. 1995.

29. Yan Z Salmons S, Jarvis J, Booth FW. Increased muscle camitine palmitoyltransferase II mRNA after increased contractile activity. Am J Physiol 1995;268:E277-81. 
30. Willian J r Wn, Padovese $r$. Oxidação dos ácidos graxos. In: Curi R, Pompéia C, Miyasaka CK, Procopio J. editors. Entendendo a gordura. Os ácidos graxos. Ma nole. 2002.

31. Winder WW. Malonyl CoA as a metabolic regulator. In: Maughan RJ, Shirreffs SM editors, Biochemistry of exerc ise IX, Human kinetics Publishers: Champaign, 1996.

32. Hageman FC. Energy metabolism and fuel utilization. Med Sci Sports Exerc 1992;24:S309-14.

33. J ones NL, Heigenhauser GJ , Kuksis A, Matsos CG, Sutton R, Toews CJ. Fat metabolism in heavy exerc ise. Clin Sci 1980;59:469-78.

34. Romijn J A, Coyle EF, Sidossis LS, Zhang XJ, Wolfe RR. Relationship between fatty acid delivery and fatty acid oxidation during strenuous exercise. J Appl Physiol 1995; 79:1939-45.

35. Amer $P$, Kriegholm E, Engfeldt $P$, Bolinder J. Adrenerg ic regulation of lipolysis in situ at rest and during exercise. J Clin Invest 1990;85:893-8.

36. Sahlin K, Katz A, Broberg S. Tric arboxylic acid cycle intermediates in human muscle during prolonged exercise. Am J Physiol 1990;259:C 834-41.

37. Savard R, Despres J P, Marcotte M, Theriault G, Tremblay A, Bouchard C. Acute effects of endurance exerc ise on human adipose tissue metabolism. Metabolismo 1987; $36: 480-5$.

38. La mbert EV, Hawley J A, Goedecke J , Noakes TD, Dennis SC. Nutritional strategies for promoting fat utilization and delaying the onset of fatigue during prolonged exercise. J Sports Sci 1997;15:315-24.

39. Bergstrom J, Hermansen L, Hultman E, Saltin B. Diet, muscle glycogen and physical performance. Acta Physiol Scand 1967;71:140-50.

40. Galbo H, Stallknecht B. Regulation of fat metabolism in exerc ise. In: Maughan RJ, Shireffs SM. editors. Biochemistry of exercise IX, Human kinetics Publishers: Champaign, 1996.
41. Decombaz J, Deriaz O, Acheson K, Gmuender B, $J$ equier $E$. Effect of L-camitine on submaximal exerc ise metabolism after depletion of muscle glycogen. Med Sci Sports Exerc 1993;25:733-40.

42. Williams MH. Nutritional ergogenics in athletics. J Sports Sci 1995;13:S63-74.

43. Graham TE. Caffeine and exercise: metabolism, endurance and performance. Sports Med 2001;31(11):785-807.

44. G lisezinski I, et al. Endurance traning changes in lipolytic responsiveness of obese adipose tissue. Am J Physiol (Endocrinol Metab) 1998;275:E951-6.

45. Gibala MJ, Young ME, Taegtmeyer H. Ana plerosis of the citric acid cycle: role in energy metabolism of heart and skeletal muscle. Acta Physiol Scand 2000;168:657-65.

46. Lancha J r AH, Recco MB, Curi R. Pyruvate carboxylase activity in the hearth and skeletal muscles of the rat. Biochem Mol Biol Int 1994;32:483-9.

47. McGamy J D. Glucose-Fatty acid interactions in health and disease. Am J Clin Nut 1998;67:500S-504S.

48. Ruderman N, Saha AK, Vavvas D, Witters LA. MalonylCoA, fuel sensing and insulin resistance. Am J Physiol Endoc Metab 1999;276:E1-E18.

49. Haber EP, Ximenes HMA, Procópio J, Carvalho CRO, Curi R, Caminelli AR. Pleiotropic effect of fatty acids on pancreatic $\beta$-cells. J Cell Physiol 2002;194:1-12.

\section{Endereço para comespondência:}

Rui Curi

Instituto de Ciências Biomédicas-USP, ICB1

Av. Prof. Lineu Prestes 1524

05509-900, São Paulo, SP

Fax: (11) 3091-7285

e.mail: ruic uri@fisio.icb.usp.br 